\title{
THE USING OF LUCILIA CUPRINA MAGGOTS IN THE TREATMENT OF DIABETIC FOOT WOUNDS
}

\author{
By
}

\author{
MOSTAFA I. HASSAN, KOTB M. HAMMAD, MOHAMAD A. FOUDA \\ AND MOHAMMAD R. KAMEL \\ Department of Zoology and Entomology, Faculty of Science, Al-Azhar University, Nasr \\ City, Cairo, Egypt (e-mail: mostafa012@gmail.com)
}

\begin{abstract}
In the present study, Lucilia cuprina maggots were used for the treatment of diabetic foot wounds. An artificial wound was made in diabetic foot of rabbit. The maggots were sterilized and put directly on the wound after dressing the wound without using any antibiotics. Several cycles of maggots were put on the wound. The present results showed that the treatment of the diabetic foot was observed after 13 days. After this period the wound was completely healed and become free of microbial contamination. The new tissues were observed to close the wound.
\end{abstract}

Keywords: Lucilia cuprina, Maggots, Rabbit, Diabetic, Wounds, Treatment.

\section{Introduction}

Maggot debridement therapy has been used for centuries. It was first acknowledged by military surgeons who noted faster healing of wounds with maggots (Baer, 1931). In the last years of the twentieth century, the maggot debridement therapy became more popular. Recently an increase in antibiotic resistant strains of bacteria and in diabetic foot and pressure ulcers (Sherman et al, 2000; Armstrong et al, 2002 and Bekins, 2010).

The debridement is defined as the removal of dead or necrotic tissue to prevent infection and to improve healing, to avoid wound delay which would provide a breeding ground for bacteria leading to gangrene, probable amputation and the possible septicemia (Bekins, 2010). Maggot's debridement has been suggested to work by mechanical and biochemical techniques (Mumcuoglu et al, 2001; Chambers et al, 2003). Maggots produce excretions and secretion (ES) that possess proteolytic enzymes that can dissolve the dead and/or infected matrix on the wound bed (Chambers et al, 2003). Maggots ES can prevent, inhibit, and break down biofilms of various bacteria (Cazander et al, 2009).
The present work aimed to study the using of Lucilia cuprina maggots in treatment of diabetic foot wounds in rabbits.

\section{Materials and Methods}

The Lucilia cuprina (Diptera: Calliphoridae) were collected from Tonamel, Village, Aga Center, Al-Dakahlia Governorate, Egypt. Maggots were reared for several generation under controlled conditions of temperature $26 \pm 2^{\circ} \mathrm{C}$, relative humidity $70 \pm 10 \%$ and $12-12$ light-dark regime in the Research Laboratory of Medical Entomology, Faculty of Science, Al-Azhar University, Cairo. The identification of flies followed the pictorial key of Dodge (1953).

The animals used were female of New Zealand rabbits; they were reared in rabbit battery and daily provided with water and food. They weights were ranged from $1 \mathrm{~kg}$ to $2 \mathrm{~kg}$. For prepare the diabetic rabbits the rabbit injected by alloxan $(145 \mathrm{mg} / \mathrm{Kg}$ of rabbit) in marginal ear vein according to Etuk (2010). After injection, the rabbits were allowed to consume $10 \%$ glucose and fructose solution. After $48 \mathrm{~h}$. and $120 \mathrm{~h}$. from injection; The Sugar in blood measured was by Gluco-Dr (Blood glucose test meter). Hairs of rabbit's legs were removed firstly by shave machine 
then hair removal cream. The wound $(2 \times 2 \times$ $1 \mathrm{~cm}$ ) was made by scalpel in the legs of rabbits; and left for 3 days to be contaminated then a piece of sponge was set around the wound. To prevent damage of the wound by rabbit mouth; two pieces from wood $(15 \times 20$ $\mathrm{cm}$ ) called Collar set around the neck of rabbit by doornails. The maggots of L cuprina were washed by $\mathrm{NaOH} 9 \%$ then sterilized by ethyl alcohol $70 \%$ for $2 \mathrm{sec}$. After sterilization the maggots were placed on the wound as 5 to 10 maggots $/ \mathrm{cm}^{3}$ (Gottrup and Jørgensen, 2011) then dressed by clean Medical Gauze. Photographs of the wound were taken with a 16 megapixel digital camera.

\section{Results}

Hairs of untreated diabetic rabb- its leg were removed, the wound was carried out (Fig. 1), and left for 3 days, to be contaminated (Fig. 2). After 2 days (Fig. 3), the healing of diabetic wound was delayed and with dirty smell, and the rabbit died on the $6^{\text {th }}$ day due to the increased sugar level in blood (Hyperglycemia).The wound was made in legs of treated diabetic rabbit (Fig. 4) and left for 3 days to become contaminated (Fig. 5). L. Cuprina maggots were placed on the diabetic wound and covered by dressing $\left(1^{\text {st }}\right.$ cycle $)$. In the $5^{\text {th }}$ day, maggots were removed from the treated diabetic wound. The healing appeared to be start (Fig. 6). After $2^{\text {nd }}$ cycle of maggots in the $6^{\text {th }}$ day, the healing of the wound continued and new tissues were observed to be grown (Fig. 7). Healing continued in treating diabetic wound, as observed after the removal of the $3^{\text {rd }}$ cycle of maggots on the $7^{\text {th }}$ day (Fig. 8). Besides, more tissues healing were noticed grown after $4^{\text {th }}$ cycle in the $8^{\text {th }}$ day (Fig. 9). The diameter of treated diabetic wound is decreased after cycle 5 in the $9^{\text {th }}$ day (Fig. 10). After the 11 days (7 cycles), 95\% of the diabetic wound is healed (Fig. 11).

The completely healing of the wound was clearly observed after the $13^{\text {th }}$ day (Fig. 12).

\section{Discussion}

The maggot debridement therapy (MDT) has been shown as a safe and low cost- effective treatment in contrast to the less selective surgical debridement and the use of expensive antibiotics (Gottrup and Jørgensen, 2011). Also, MDT has saved from amputation about $50 \%$ of limbs in which it has been tried (Sherman et al, 2001; Jukema et al, 2002; Sherman, 2002). In agreement with the present study, the maggot debridement therapy (MDT) with Lucilia cuprina proved as effective as the known conventional debridement in the treatment of diabetic wound where, Paul et al. (2009) used maggots of Lucilia cuprina for treating 29 patients suffered from diabetic foot wounds, 14 wounds were healed, 11 were unhealed and 4 were classified under others. The control group treated by conventional debridement had 30 patients of which 18 wounds were healed, 11 unhealed and 1 classified under others. Also, Kingu et al. (2012) and Tantawi et al. (2010) are suggested using L. cuprina in maggot debridement therapy. Bekins (2010) evaluated five studies, all showed that maggot debridement therapy was effective in debriding wounds; the present data was agreed with the author in the effectiveness of maggot debridement therapy in debriding wounds.

The present data showed an indication of using L. cuprina maggots in debriding the normal and diabetic wounds in rabbits (the wound debrided after 9 days and 13 days respectively). These results agreed with the results of Preuss (2004) in a case report of a 73year-old woman suffered from necrotizing fasciitis of the neck, where he used MDT in this case, and the maggots perform three mechanisms of action: and clean wounds by dissolving dead and infected tissue, the maggots disinfected the wound, by killing the superimposed bacteria and the maggots stimulated the wound healing. Maggot debridement therapy (MDT) is used by a few small animal veterinarians to debride difficult wounds and proved useful for debriding and disinfecting some serious wounds (Sherman et al, 2007).

The successful use of Lucilia cuprina maggot therapy went with the results reported in the 
bull (Dicke, 1953), donkey (Bell and Thomas, 2001; Thiemann, 2003), dogs, cats and rabbits (Sherman et al, 2007) and horses (Sherman et al, 2007).

On the other hand, from medical point of view, Al-Wahbi (2006) reported that the prevalence of diabetic foot ulcers in the Arab world in general was high, compared with Western countries and that few studies illustrated the efficacy and associated healing mechanisms of local therapy of progenitor cells in a preclinical model of the diabetic ischaemic foot ulcer ( $\mathrm{Gu}$ et al, 2007). ElSharawy et al. (2012) in Egypt stated that diabetic patients with foot ulcers usually were manifested with high amputation and mortality rates and that treatment with the CD34+enriched cells decreased wound size, accelerated epidermal healing and dramatically accelerated revascularization of wounds compared with the DC group. Assaad-Khalil et al. (2013) in Egypt stated that physicians in the Middle East and South Africa identified limitations relating to their patients as the main barrier to delivering care for diabetes, without giving high priority to issues relating to processes of care delivery. Further study would be needed to ascertain whether these findings reflect an unduly physician-centred view of their practice. More effective provision of services relating to the prevention of complications and improved lifestyles may be needed. El-Hilaly et al. (2013) in Egypt reported that in diabetic subjects, re-ulcerations following first ray amputations are particularly frequent and that treatment usually includes an in-shoe intervention to reduce plantar pressure. They concluded that the conforming total contact insole showed significant reduction in plantar pressures in patients with first ray amputation.

\section{Conclusion}

Generally speaking, diabetic foot is more or less a worldwide complicated health problem as well as in the Arab countries including Egypt.
The outcome data recommended the using of Lucilia cuprina maggots in maggot debridement therapy in humans or animals wounds.

\section{References}

Al-Wahbi, AM, 2006: The diabetic foot in the Arab world. Saudi Med J. 27:147-53.

Armstrong, DG, Mossel, J, Short, B, Nixon, BP, Knowles, EA, et al, 2002: Maggot debridement therapy: A primer. J. Amer. Pediatr. Med. Assoc. 92, 7:398-401.

Assaad-Khalil, SH, Al Arouj, M, Almaa-touq, M, Amod, A, Assaad, SN, et al, 2013: Barriers to the delivery of diabetes care in the Middle East and South Africa: a survey of 1,082 practising physicians in five countries. Int. J. Clin. Pract. 67, 11: 1144-50.

Baer, WS, 1931: The treatment of chronic osteomyelitis with the maggot. J. Bone Joint Surg.13, 3:438-75.

Bekins, L, 2010: Maggot Therapy for Removal of Non-healing Wounds. Masters of Science Degree, Faculty of the School of Ph-ysician Assistant Studies, Pacific University.

Bell, NJ, Thomas, S, 2001: Use of sterile maggots to treat panniculitis in an aged donkey. Vet. Rec. 149, 25:768-70.

Cazander, G, van Veen, KE, Bouwman, L H, Bernards, AT, Jukema, GN, 2009: The influence of maggot excretions on PAO1 biofilm formation on different biomaterials. Clin. Orthopaed. Rel. Res. 467, 2:536-45.

Chambers, L, Woodrow, S, Brown, AP, Harris, PD, Phillips, D, et al, 2003: Degradation of extracellular matrix components by defined proteinases from the green-bottle larva, Lucilia sericata used for the clinical debridement of nonhealing wounds. Brit. J. Der-matol. 148, 1:14-23.

Dicke, RJ, 1953: Maggot Therapy of Actinomycosis. J. Econ. Entomol. 46, 4:706-7.

Dodge, HR, 1953: Domestic flies: pictorial key to common species in southern US In: CDC Pictorial Keys: Arthropods, Reptiles, Birds and Mammals of Public Health Significance.

El-Hilaly, R, Elshazly, O, Amer, A, 2013: The role of a total contact insole in diminishing foot pressures following partial first ray amputation in diabetic patients Foot (Edinb). 23, 1:6-10

Elsharawy, MA, Naim, M, Greish, S, 2012: Human CD34+ stem cells promote healing of di- 
abetic foot ulcers in rats. Interact. Cardiovasc. Thorac. Surg. 14, 3:288-93.

Etuk, EU, 2010: Animals models for studying diabetes mellitus. Agricul. Biol. J. North Amer. 1, 2:130-4.

Gottrup, F, Jørgensen, B, 2011: Maggot debridement: an alternative method for debridement. Eplasty, 11, 290-302

Gu, Y, Zhang, J, Qi. L, 2007: Comparative study on autologous implantation between bone marrow stem cells and peripheral blood stem cells for treatment of lower limb ischemia. Zhongguo Xiu Fu Chong Jian Wai Ke Za Zhi. 21:675-8

Jukema, GN, Menon, AG, Berna- rds, AT, Steenvoorde, P, Rastegar, AT, et al, 2002: Amputation-sparing treatment by nature: Sur-gical maggots revisited. Clin. Infect. Dis. 35, 12:156671.

Kingu, JH, Kuria, KS, Villet, HM, Mkhize, NJ, Dhaffala, A et al, 2012: Cutaneous Myiasis: Is Lucilia cuprina safe and acceptable for maggot debridement therapy. J. Cosmet. Dermatol. Sci. Applica. 2:79-82.

Mumcuoglu, KY, Miller, J, Mumcuoglu, M, Friger, M, Tarshis, M, 2001: Destruction of bacteria in the digestive tract of the maggot of Lucilia sericata (Diptera: Calliphoridae). J. Med. Entomol. 38, 2:161-6.

Paul, AG, Ahmad, NW, Lee, HL, Ariff, A M, Saranum, M, et al, 2009: Maggot debridement therapy with Lucilia cuprina: a comparison with conventional debridement in diabetic foot ulcers. Int. Wound J. 6, 1:39-46.

Preuss, SF, Stenzel, MJ, Esriti, A, 2004: The successful use of maggots in necrotizing fasciitis of the neck: a case report. Head Neck 26, 8:74750.

Sherman, RA, Hall, MJR, Thomas, S, 2000: Medicinal maggots: an ancient remedy for some contemporary afflictions. Ann. Rev. Entomol. 45, 1:55-81.

Sherman, RA, Morrison, S, Ng, D, 2007: Maggot debridement therapy for serious horse wounds-a survey of practitioners. Vet. J. 174, 1:86-91.

Sherman, RA, Sherman, J, Gilead, L, Lipo, M, Mumcuoglu, KY, 2001: Maggot debridement therapy in outpatients. Arch. Physi. Med. Rehabilitat. 82, 9:1226-9.

Sherman, RA, Stevens, H, Ng, D, Iversen, E, 2007: Treating wounds in small animals with maggot debridement therapy: a survey of practitioners. Vet. J. 173, 1:138-43.

Tantawi, TI, Williams, KA, Villet, MH, 2010: An accidental but safe and effective use of Lucilia cuprina (Diptera: Calliphoridae) in maggot debridement therapy in Alexandria, Egypt. J. Med. Entomol. 47, 3:491-4.

Thiemann, A, 2003: Treatment of a deep injection abscess using sterile maggots in a donkey: a case report. World Wide Wounds.

Fig. 1: Untreated wound in diabetic rabbit leg at a zero day.

Fig. 2: Untreated wound in diabetic rabbit leg after 3 days, wound contaminated.

Fig. 3: Untreated wound in diabetic rabbit leg after 5 days, wound delayed in healing.

Fig. 4: Treated wound in diabetic rabbit with maggots at a zero day.

Fig. 5: Treated wound in diabetic rabbit with maggots after 3days, wound contaminated

Fig. 6: Treated wound in diabetic rabbit with maggots after 5 days (one cycle), healing started.

Fig. 7: Treated wound in diabetic rabbit with maggots after 6 days ( 2 cycles). Post maggots' removal, healing appeared.

Fig. 8: Treated wound in diabetic rabbit with maggots after 7 days ( 3 cycles). Post maggots' removal, tissues continue healing.

Fig. 9: Treated wound with maggots after 8 days (4 cycles). Post removed maggots, tissues continued to heal and new layers of tissues appeared.

Fig. 10: Treated wound in diabetic rabbit with maggots after 9 days (5 cycles). Post maggots' removal diameter of diabetic wound decreased.

Fig. 11: Treated wound in diabetic rabbit with maggots after 11 days (7 cycles). Post maggots' removal and hard layer, new tissues' layers appeared.

Fig. 12: Treated wound in diabetic rabbit with maggots after 13 days (7 cycles), wound completely healed. 

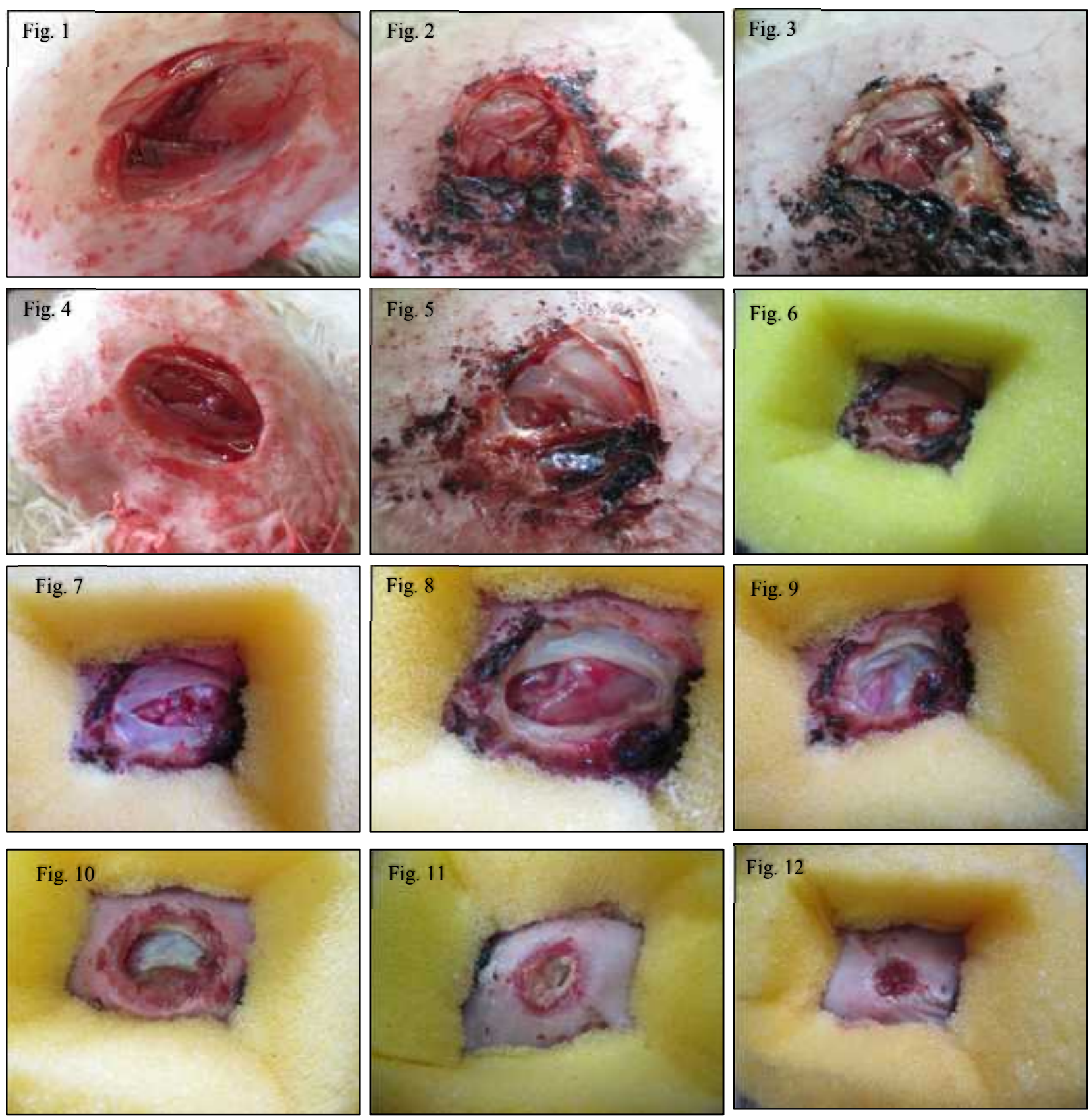